\title{
UMA DISCUSSÃO DE FORMA LÚDICA, SOBRE A SEXUALIDADE E MÉTODOS PREVENTIVOS-CONTRACEPTIVOS COM ADOLESCENTES DA REDE ESTADUAL DE ENSINO
}

\author{
Giuliano Roberto da SILVA ${ }^{1}$ \\ Júlia Moretto AMÂNCIO ${ }^{2}$ \\ Líbia Aparecida CARLOS ${ }^{3}$
}

RESUMO: Neste estudo foi feito uma experiência prática no campo da "Educação Física Escolar", explorando a sexualidade em jovens de 13 a 15 anos de idade de uma escola de Minas Gerais. O objetivo foi fornecer informações, promovendo discussões a respeito de assuntos relacionados com sexualidade, doenças sexualmente transmissíveis, namoro versus ficar, e o uso de métodos preventivo-contraceptivos, contribuindo para boa educação sexual dos jovens. Foram empregados: palestra sobre sexualidade, dinâmica de grupo, debates e demonstração de métodos preventivo-contraceptivos e a utilização de um jogo lúdico didático de perguntas e respostas com o objetivo de medir o conhecimento adquirido durante as oficinas práticas. Ao final percebeu-se aumento no nível de conhecimento dos adolescentes, favorecendo a adoção de boas práticas de comportamento sexual responsável e preventivo.

PALAVRAS-CHAVE: Adolescentes. Sexualidade. Prevenção.

\section{Introdução}

Os profissionais educadores da rede estadual ou privada têm notado em suas vivências profissionais, certa dificuldade dos familiares em orientar seus filhos, sobre sexo e sexualidade (SANTOS 1994). Mediante a isso nós educadores percebemos a necessidade de promover debates, dinâmicas e palestras sobre esses temas com o intuito de agregar uma melhor formação psicológica, social e integral dos adolescentes na sociedade civil. Segundo Rizek (2003), essas alternativas irão contribuir na preparação de um futuro cidadão mais esclarecido, com melhores condições para saber discernir o que é certo e errado assim como saber o momento adequado para se relacionarem com segurança e responsabilidade, evitando transtornos como, por exemplo, doenças sexualmente transmissíveis (DSTs), gravidez precoce, etc. Situações essas que

\footnotetext{
${ }^{1}$ Doutorando em Promoção de Saúde. UNIFRAN - Universidade de Franca. Franca - SP - Brasil. giumusc@gmail.com.

2 Professora adjunta de Gestão de Políticas Públicas. UFLA - Universidade Federal de Lavras. Departamento de Administração e Economia. Lavras - MG - Brasil. 37200-000 jumorettoamancio@gmail.com.

${ }^{3}$ Professora efetiva na Rede Municipal na cidade de Lavras - Secretaria Municipal - Lavras - MG Brasil. 37200-000 - libia.carlos@ gmail.com.
} 
normalmente refletem prejuízos de ordem social como na saúde, alimentação, transporte, segurança e educação.

É de fundamental importância que a escola possa prover informações corretas e claras sobre o sexo e sexualidade, pois, vários estudos demonstram que os jovens estão transando cada vez mais cedo e sem nenhuma responsabilidade e isso acarretam uma gravidez precoce indesejada, DSTs, abuso sexual, utilização de drogas associadas, etc (JIMÉNEZ et al., 2001; TRAJMAN et al., 2003). Mesmo nos dias atuais com tantas evoluções tecnológicas em favor da comunicação (estampado em programas de televisão, músicas, revistas e nas redes sociais que fazem parte de nosso dia a dia) ainda é tão difícil falar sobre sexo e sexualidade, dificuldade está caracterizada na falta de tempo, de conhecimento teórico dos pais e responsáveis sobre o assunto para saberem esclarecer e opinar de uma maneira correta com seus filhos.

Para isso se faz necessária à aproximação destes alunos para sabermos suas reais dúvidas e curiosidades, proporcionando sugestões e atividades que poderão ser trabalhadas a favor de uma vida sexual segura e de métodos contraceptivos preventivos nas relações entre os gêneros nas escolas e até mesmo dentro do ambiente familiar, através de iniciativas (oficinas) práticas com é a proposta desse artigo.

Sendo a sexualidade um assunto ainda cheio de tabus até mesmo nos adultos, não podemos exigir deles informações, porque a educação que eles tiveram sobre sexualidade os leva a não se sentirem a vontade para comentar com os adolescentes sobre este assunto. A maioria dos pais não gostam de falar sobre sexo e sexualidade, porque chegar a esse ponto do dialogo entre pais e filhos, é admitir que seu filho(a) está crescendo e querendo conhecer o mundo em suas diferentes experiências. E todo mundo sabe que os pais acham que seus filhos sempre serão crianças, então não se sentem bem em falar sobre um assunto tão censurado quanto o sexo, apesar de que, toda regra tem sua exceção, todavia temos pais que se sentem a vontade e seguros para falar sobre este assunto (TESSARI, 2008).

Mediante tais situações esboçadas acima, acreditamos que isso promoverá uma confusão na cabeça dos adolescentes, confusão essa caracterizada pelo grande acúmulo de informações vindas da mídia (televisão, internet, revistas, etc) às vezes distorcidas, ou, quando os pais e responsáveis omitem ou fantasiam assuntos relacionados sobre sexualidade e sexo, a qual em muitas oportunidades evitam falar sobre o assunto, criando verdadeiros tabus. 
De acordo com Tiba (1998, p.32) "ensinar é um gesto de generosidade, humanidade e humildade". Sendo assim se faz necessário que os pais e responsáveis e também os educadores se conscientizem que independente da faixa etária, sexo e sexualidade estão presentes e as dúvidas devem ser esclarecidas e discutidas, de maneira simples e objetiva, com humildade.

Para tanto, nesse artigo o objetivo principal foi de orientar e discutir através de um ensaio prático com os adolescentes, no sentido de buscar maneiras para suprir as dúvidas e questionamentos indagados por eles, também orientar os adolescentes com relação a sua conduta sexual e de sexualidade, demonstrar noções de métodos contraceptivos e de prevenção de doenças sexualmente transmissíveis, assim como colaborar com a formação integral dos adolescentes, promovendo a eles conhecimento específico sobre sua fisiologia sexual, mudando a sua trajetória de pensamento sobre a vida, não se deixando levar apenas por fantasias, emoções, ou impulsos que mais tarde poderá acarretar prejuízos para seu desenvolvimento social, como doenças sexualmente transmissíveis e gravidez indesejada.

\section{A construção da sexualidade na adolescência}

De acordo com Palácios (1995), a puberdade refere-se ao período do processo de constituição dos sujeitos no qual se dá o surgimento da atividade hormonal que desencadeia os caracteres sexuais secundários - aproximadamente, entre os nove e quatorze anos de idade.

Tendo em vista a compreensão plural da adolescência, ou seja, a dificuldade de tratar esse assunto com os jovens frente às mudanças drásticas que estão ocorrendo com sua fisiologia, ou de entendimento do próprio adolescente que norteia este projeto, concorda-se com Caridade (1999), quando afirma que a compreensão da sexualidade vivida pelos adolescentes deve ser contextualizada culturalmente, na medida em que a sexualidade é constituída a partir da cultura em que estes se inserem.

A inclusão da sexualidade no currículo das instituições de ensino tem se intensificado a partir da década de 70, por ser considerada imprescindível na formação global do indivíduo. As manifestações de sexualidade afloram em todas as faixas etárias, ignorar, ocultar ou reprimir são as respostas mais habituais dadas pelos profissionais da escola, estas práticas se fundamentam na idéia de que o tema deva ser tratado exclusivamente pela família (SANTOS, 1994). 
Os PCNs definiram a orientação sexual como um dos temas transversais que devem perpassar toda concepção e estruturação do ensino fundamental e médio em nosso país. Propõe que a "Orientação Sexual" oferecida pela escola aborde com as crianças e os jovens as repercussões das mensagens transmitidas pela mídia, pela família e pelas demais instituições da sociedade. Trata-se de preencher lacunas nas informações que a criança e o adolescente já possuem e, principalmente criar a possibilidade de formar opinião a respeito do que lhes é ou foi apresentado. A escola, ao propiciar informações atualizadas do ponto de vista científico e ao explicitar e debater os diversos valores associados à sexualidade e aos comportamentos sexuais existentes na sociedade possibilita ao aluno desenvolver atitudes coerentes com os valores que ele próprio elege como seus. Experiências bem sucedidas com a "Orientação Sexual” em escolas que realizaram esse trabalho apontam para alguns resultados importantes: aumento do rendimento escolar (devido ao alívio das tensões e preocupações com questões da sexualidade), aumento da solidariedade e respeitos entre os alunos. Quanto às crianças menores, os professores relatam que informações corretas ajudam a diminuir a angústia e a agitação em sala de aula. No caso dos adolescentes, as manifestações da sexualidade tendem a deixar de ser fonte de agressão, provocação, medo e angústia, para tornar-se assunto de reflexão (NUNES, 2000).

No que se refere à produção teórica e metodológica voltada para a adolescência, Abramo (1997) aponta a escassez de subsídios caracterizando um desencontro entre as esperanças construídas pelas famílias em torno do valor da escola e as aspirações juvenis - ascensão social, melhoria das condições de vida. Para o jovem, o desencontro das expectativas iniciais na família e a experiência cotidiana vivida nas escolas, que nega essas aspirações, pode gerar desinteresse, indisciplina e violência, na medida em que a trajetória na escolarização gera insucesso e exclusão, tornando uma fase difícil de lidar, de interagir (PATTO, 1993).

De acordo com Sampaio (1996), a sexualidade deve ser orientada de forma a preparar o individuo para a "vida sexual" sabendo diferenciar os momentos e atitudes adequadas frente às relações da sexualidade, porém para educar é preciso que o educador esteja preparado para tal tarefa.

Os tabus e preconceitos que envolvem o sexo e a sexualidade não se originam no adolescente, mas no mundo social onde está inserido. A educação sexual deverá passar primeiramente pela educação do educador, sendo que o professor deve estar consciente da beleza e dignidade do sexo e sexualidade. $\mathrm{O}$ educador deve encarar com naturalidade 
a curiosidade do jovem e adolescente, se este se omitir gerará no jovem, uma ansiedade de saber, que o fará buscar a satisfação de suas curiosidades em outras fontes nem sempre recomendáveis.

Sendo a escola um meio divulgador de tais conhecimentos sobre o funcionamento do corpo e principalmente sobre assuntos relacionados à questão do sexo e sexualidades e suas relações, poderá ser passado até mesmo para sua família promovendo uma melhor orientação familiar refletindo a extensão dos conhecimentos da escola na sociedade.

\section{Métodos}

O estudo foi realizado através de pesquisa de campo e descritiva transversal com levantamento de dados (PEREIRA, 1995). O trabalho prático foi realizado através de encontros semanais durante aulas de Educação Física, na Escola Estadual Coronel Joaquim Ribeiro (EECJR) que faz parte da $41^{\text {a }}$ SER - Delegacia de Ensino Lotada em Varginha Minas Gerais. A EECJR destina-se ao ensino fundamental desde o $1^{\circ}$ ano primário até o $9^{\circ}$ ano de ensino fundamental localizada na cidade de Nepomuceno MG. A amostra refere-se a uma classe de $9^{\circ}$ ano (4) do ciclo fundamental com idades entre 13 e 15 anos de idade, totalizando uma amostra 36 alunos compreendendo um percentual de $15 \%$ de estudantes dessa faixa etária que estão matriculados nessa escola. Essa classe foi previamente escolhida por ter uma quantidade igual entre os gêneros (18 masculinos e 18 femininos).

O método de trabalho prático foi desenvolvido através de uma pesquisa de ação participativa que compreende um tipo de pesquisa social com base empírica que é concebida e realizada em estreita associação com uma ação ou com a resolução de um problema coletivo (THIOLLENT, ARAUJO; SOARES, 2000).

Foram realizadas oficinas com duração de 50 minutos de discussão e de ação lúdica durante o horário de aulas de Educação Física, mediante a realização dessas promovidas nessa classe, percebi que os adolescentes freqüentadores desta, em geral, participaram ativamente e espontaneamente das atividades chegando a uma superação de minha proposta inicial no processo de planejamento das atividades. Foram realizadas as etapas que serão apresentadas nos tópicos a seguir. 


\section{Explanação e apresentação da proposta que será abordada no estudo prático}

Procurou-se conhecer os participantes do grupo, bem como identificar a demanda destes em relação as suas dúvidas sobre a sexualidade e sexo, sendo que o grupo feminino estava mais aberto aos diálogos em relação ao grupo masculino, principalmente sobre a questão da gravidez.

\section{Confecção de caixa de dúvidas}

Nesta etapa os jovens participantes colocaram suas dúvidas que foram debatidas e esclarecidas posteriormente, e percebi que em muitos momentos o grupo feminino estava mais aberto aos diálogos em relação ao grupo masculino, principalmente sobre a questão da gravidez. Uma das perguntas mais esboçadas na caixa de dúvidas foi de quem seria a responsabilidade de prevenir a gravidez precoce, e novamente às meninas demonstraram mais maturidade dizendo que seria uma responsabilidade dos dois durante a relação, enquanto os meninos disseram que a responsabilidade de evitar a gravidez seria delas. Percebi então, certo machismo que ainda impera em nossa sociedade, o que corrobora o estudo feito por Paiva (2000).

Figura 1 - Caixinha de Dúvidas

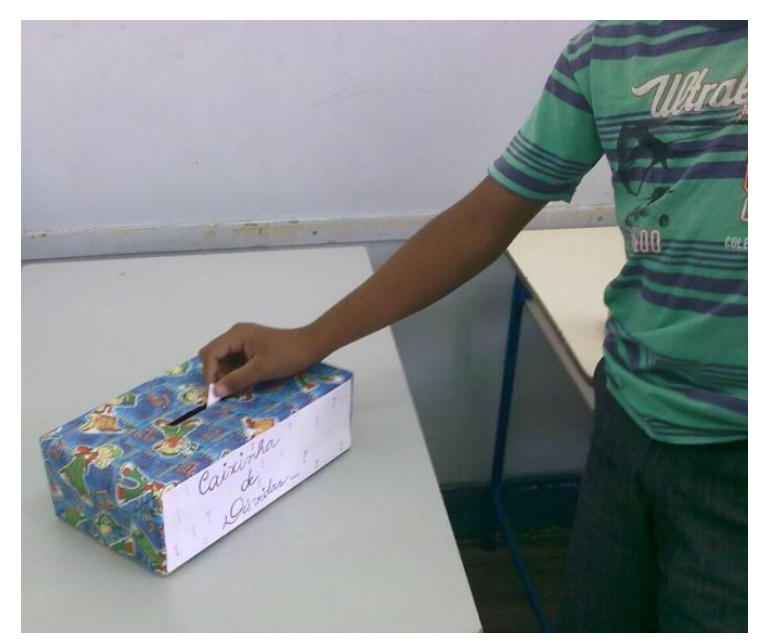

Fonte: Foto tirada pelo autor. 


\section{Confecção de desenhos: um jovem e uma jovem}

A sala foi dividida em dois grupos (masculino e feminino), e em um papel pardo foram confeccionados os desenhos e após estes eles tiveram a tarefa de nomear as figuras desenhadas e escrever ao lado dessas as qualidades e defeitos que eles achavam dos mesmos. Em seguida, cada grupo apresentou seu desenho ao outro e assim foi estabelecida uma discussão a respeito das dúvidas relacionadas à adolescência. No entanto os grupos entraram em conflito, principalmente no momento em que falaram sobre os defeitos que ambos descreveram sobre os gêneros. Mediante tal situação tive que intervir em vários momentos para apaziguar os ânimos exaltados.

Figura 2 - Desenho de uma jovem realizado pelos meninos

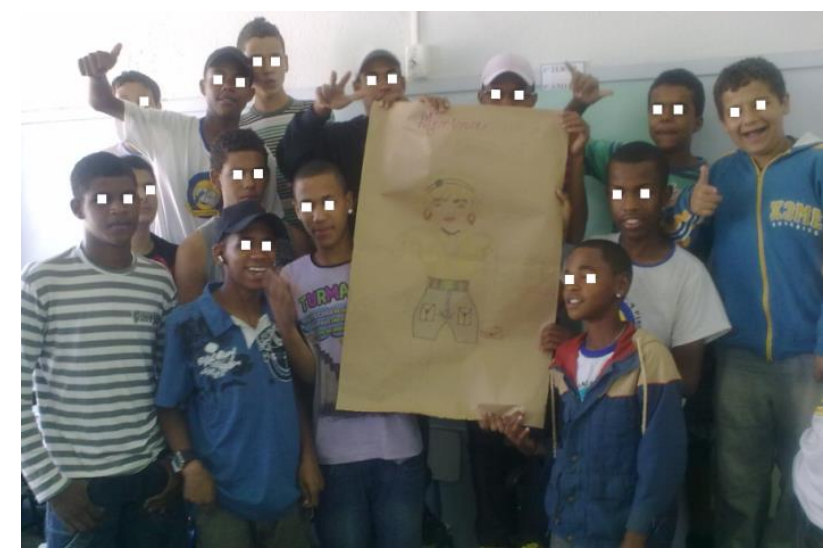

Fonte: Foto tirada pelo autor.

Figura 3 - Desenho de um jovem realizado pelas meninas

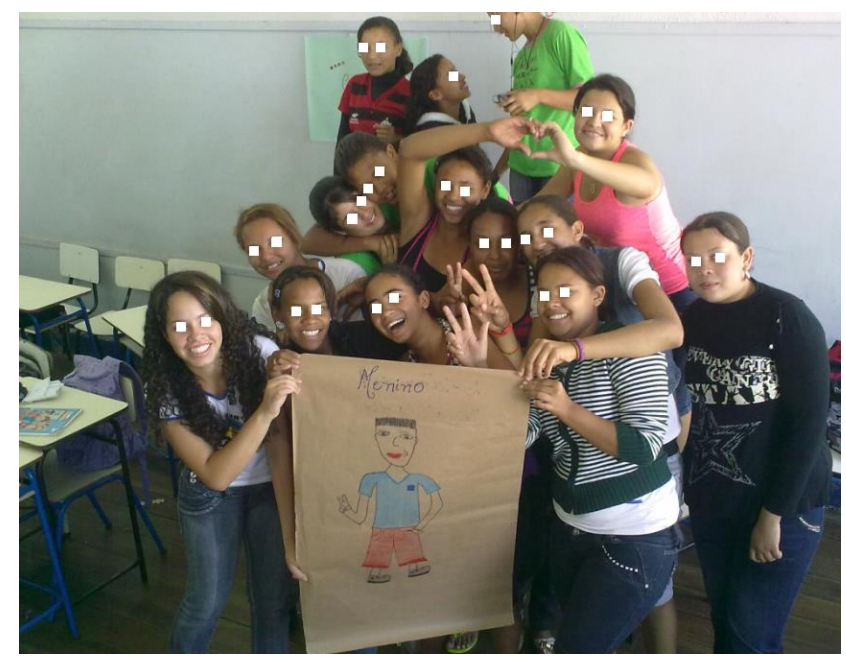

Fonte: Foto tirada pelo autor. 


\section{Ficar versus Namorar}

A cultura do "ficar" é uma relação muito superficial está disseminado e vai além das fronteiras da adolescência, jovens adultos ou não, rendem-se a essa prática (TESSARI, 2008). Para Caramaschi (2009), “ficar” não é uma mudança comportamental isolada, e sim o reflexo de uma sociedade composta por pessoas mais centradas em si mesmas, e ainda acrescenta que "ficar" pode ter a duração de um beijo, uma noite, algumas semanas, mas, sem telefonemas ou confirmação de encontros.

O namoro é aquele em que o (a) namorado (a) é apresentado (a) aos familiares e frequenta a casa. Muitos adolescentes não gostam de namorar em casa, onde a família pode exercer mais controle sobre o casal e sua sexualidade, assim como o namoro pode adquirir uma dimensão não desejada por eles, tornando-se mais sério que o pretendido. $\mathrm{Na}$ intenção de apontar o compromisso e a seriedade do namoro, a aliança de compromisso tem sido atualmente, uma prática recorrente entre adolescentes (STENGEL et. al., 2010).

Essa atividade teve como intuito verificar as opiniões dos jovens com relação à temática supracitada. Falou-se sobre as semelhanças e diferenças dessas duas situações, e dentre os gêneros, uma pequena minoria dos jovens masculinos, disseram que seria importante a dimensão afetiva em ambos os tipos de relacionamentos, tanto no "ficar" ou no namorar. Todavia o grupo feminino em sua maioria foi a favor de uma relação estável e que trará uma segurança afetiva, disseram também que à mulher que mantém longos relacionamentos ainda é mais respeitada do que aquela que se relaciona por um curto período de tempo, o que comprova os estudos de Fisher (1995), quando relata que a mulher que mantém relacionamentos duradouros geralmente será escolhida para relação estável matrimonial.

O desenvolvimento dessa atividade aconteceu de uma forma bem dinâmica, onde os participantes deveriam se deslocar do centro da sala para uma, dentre três diferentes paredes. Sendo que a primeira delas continha um cartaz com a palavra concordo, a segunda, a palavra discordo e a terceira, as palavras tenho dúvidas. Mediante sua escolha sobre as afirmativas, os jovens posicionavam-se em cada parede de acordo com seu ponto de vista e esses eram debatidos. 
Figura 4 - Meninas ao lado do cartaz "Concordo"

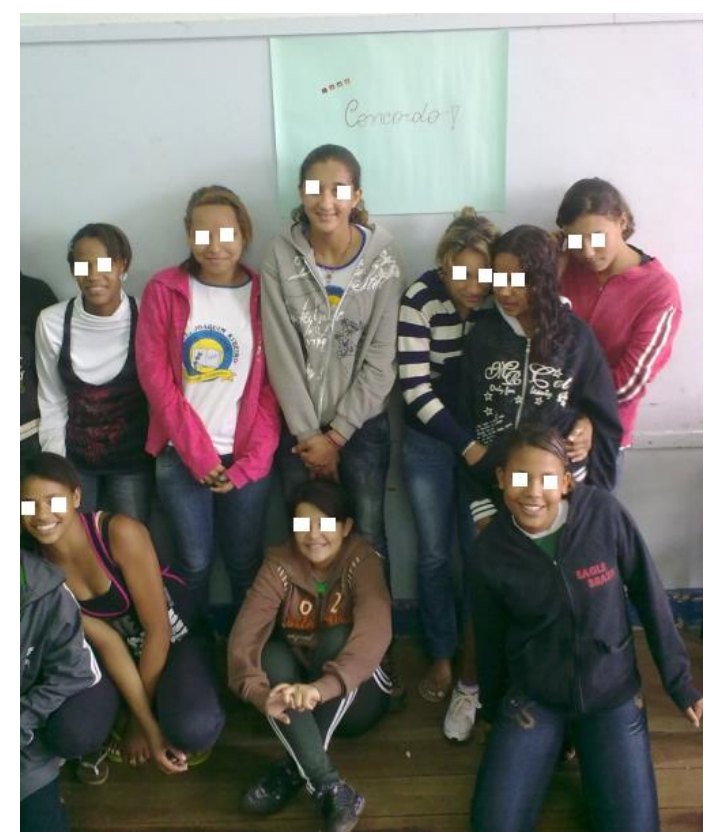

Fonte: Foto tirada pelo autor.

Figura 5 - Meninos ao lado do cartaz "Discordo"

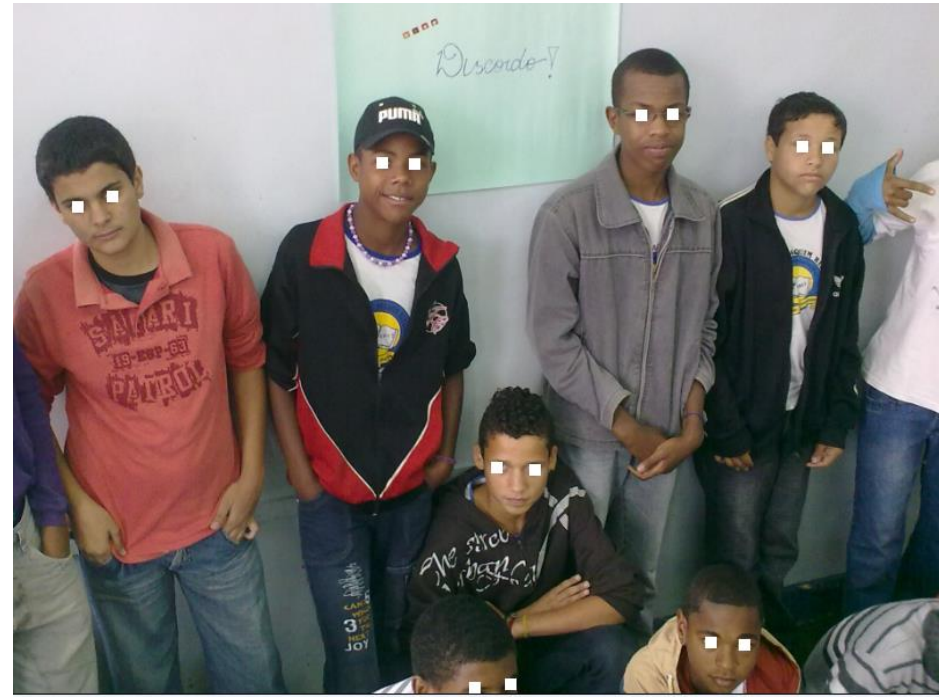

Fonte: Foto tirada pelo autor.

\section{Material lúdico: "Aprendendo a viver”}

Este material é um guia de estudo constituído em forma de jogos lúdicos (perguntas e respostas), sobre os temas menstruação, masturbação, pênis, vagina, doenças sexualmente transmissíveis (DSTs), gravidez, e métodos contraceptivos, contendo também próteses (masculina e feminina), com o objetivo de demonstrar os métodos de contracepção. 
Figura 6 - Material Lúdico

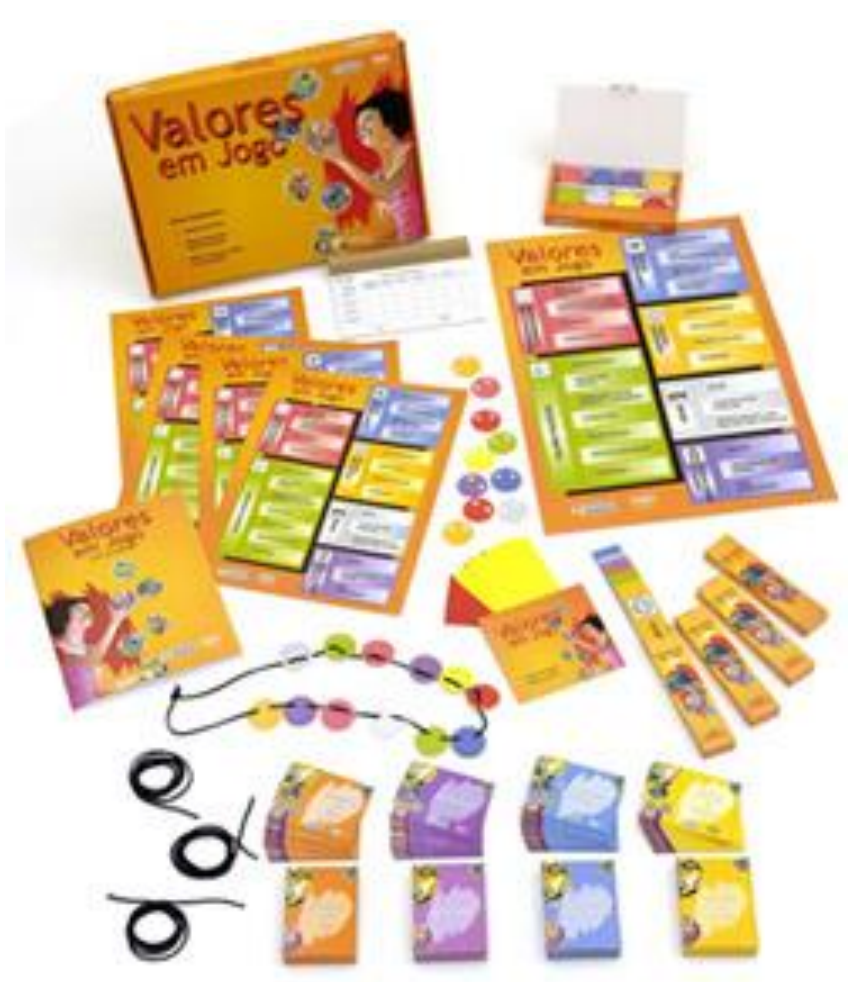

Fonte: Instituto Kaplan ${ }^{4}$.

Inicialmente houve certo desconforto, vergonha, risos, principalmente na visualização da prótese masculina. No ensaio prático de simulação do uso de preservativo, percebi certa recusa por parte de alguns meninos em não querer pegar na prótese masculina, ouvi até mesmo a seguinte argumentação: “que homem que é homem não pega de jeito nenhum em outro pênis mesmo que este seja de borracha", percebo aí a famosa questão do machismo que ainda impera na sociedade. Porém, com minha explicação e insistência durante a demonstração os jovens começaram a interagir de uma maneira mais satisfatória.

\section{Considerações finais}

Nesta experiência profissional, pude explorar as questões referentes à adolescência e sexualidade, de uma forma bastante dinâmica e com responsabilidade no que se refere ao relacionamento sexual.

Nesse ínterim, durante a realização de cada encontro notei a mudança de comportamento e de conhecimento sobre os termos versados na sala de aula. Nas

${ }^{4}$ Disponível em: <http://www.kaplan.org.br/institucional/sec/jogos $>$. Acesso em: 1 mar. 2015. 
primeiras aulas práticas (oficinas) a falta de conhecimento era evidente na maioria dos gêneros, por exemplo, termos como: Doenças sexualmente transmissíveis (DSTs), métodos contraceptivos, orgasmos, impotência sexual, libido, etc.

No decorrer dos encontros os jovens passaram a participar mais nas atividades e principalmente a compartilhar informações que foram assimilando no decorrer dos ensaios práticos, facilitando bastante suas respostas corretas que eram abordadas no jogo lúdico “Aprendendo a Viver”.

O resultado deste ensaio prático possibilitou uma reflexão a respeito da importância da realização de atividades de educação sexual, focalizando mitos, crenças, e tabus, não só com os jovens estudados, mas, também com seus familiares, visto que seus valores parecem exercer certa influência no comportamento dos jovens, por exemplo, no caso dos meninos que demonstraram um "machismo" bastante explicito durante as atividades.

\section{A DISCUSSION OF PLAYFUL FORM, ABOUT SEXUALITY AND PREVENTIVE METHODS - CONTRACEPTIVES WITH TEENAGERS IN A STATE SCHOOL NETWORK}

ABSTRACT: This study was done with practical experience in the field of "Physical Education" exploring sexuality in young people 13-15 years old from a school of Minas Gerais. The objective was to provide information, promote discussion on issues related to sexuality, sexually transmitted diseases, dating versus staying, and the use of preventative, contraceptive methods, contributing to good sex education for young people. Were used: lecture on sexuality, group dynamics, discussion and demonstration of preventive-contraceptive methods and the use of a didactic playful game of questions and answers in order to measure the knowledge acquired during the practical workshops. At the end noticed an increase in the level of knowledge among adolescents and encouraging the adoption of best practices in responsible and precautionary sexual behavior.

KEYWORDS: Teens. Sex. Prevention.

\section{REFERÊNCIAS}

ABRAMO, H. W. Considerações sobre a tematização social da juventude no Brasil. Revista Brasileira de Educação, Rio de Janeiro, núm. esp., p.25-36, 1997.

CARAMASCHI, S. et al. Seleção de parceiros: Diferenças entre gêneros em diferentes contextos. Psicologia Argumento, Curitiba, v.27, n.57, p.117-129, abr./jun. 2009. 
CARIDADE, A. O adolescente e a Sexualidade. In: SCHOR, N.; MOTA, M. do S. F. T.; CASTELO BRANCO, V. (Org.). Cadernos Juventude, saúde e desenvolvimento Brasília: Ministério da Saúde/ Secretária de Políticas de Saúde, 1999. p.206-212.

FISHER, H. Anatomia do amor: a história natural da monogamia, do adultério e do divórcio. São Paulo: Eureka, 1995.

JIMÉNEZ, A. L. et al. Prevenção de doenças sexualmente transmissíveis em mulheres: associação com variáveis socioeconômicas e demográficas. Cadernos de Saúde Pública, Rio de Janeiro, v.17, n.1, p.55-62, 2001.

NUNES, C., SILVA, E. A educação sexual da criança. São Paulo: Autores

Associados, 2000.

PAIVA, V. Fazendo Arte com a camisinha: Sexualidades Jovens em Tempos de Aids. São Paulo: Summus, 2000.

PALÁCIOS, J. O que é a adolescência. In: COLL, C.; MARCHESI, A.; PALÁCIOS, J. Desenvolvimento psicológico e educação. Porto Alegre: Artes Médicas, 1995. p.263273.

PATTO, M. H. S. A produção do fracasso escolar. São Paulo: Queiroz, 1993.

PEREIRA, M. Epidemiologia Teoria e prática 3.ed. Rio de Janeiro: Guanabara Koogan, 1995.

RIZEK, C. S. Sociedade civil e espaços públicos no Brasil: um balanço necessário. Revista Brasileira de Ciências Sociais, São Paulo, v.18, n.51, 2003.

SAMPAIO, S. Educação sexual para além dos tabus. Salvador: UFBA, 1996.

SANTOS, Z. Sexualidade na adolescência, 1994. Disponível em:

<http://www.webartigos.com/artigos/sexualidade-na-adolescencia/6952/>. Acesso em: 12 fev. 2015.

STENGEL, M. et al. Projetos afetivo-sexuais por adolescentes e seus pais. Pesquisas e Práticas Psicossociais, São João del-Rei, MG, v.5, n.1, jan./jul. 2010.

TESSARI, O. I. Dirija sua vida sem medo. 2.ed. São Paulo: Letras Jurídicas, 2008.

TIBA, I. Ensinar aprendendo: como superar os desafios do relacionamento professor-aluno em tempos de globalização. São Paulo: Gente, 1998.

THIOLLENT, M.; ARAUJO, T.; SOARES, R. Metodologia e Experiência em projetos de extensão. Niterói: Ed. Da UFF, 2000.

TRAJMAN, A. et al. Knowledge about STD/AIDS and sexual behavior among high school students in Rio de Janeiro, Brazil. Cadernos de Saúde Pública, Rio de Janeiro, v.19, n.1, p.127-133, 2003. 